\title{
Bromelain Inhibits Allergic Sensitization and Murine Asthma via Modulation of Dendritic Cells
}

\author{
Eric R. Secor Jr., ${ }^{1,2}$ Steven M. Szczepanek, ${ }^{3}$ Christine A. Castater, ${ }^{2}$ \\ Alexander J. Adami, ${ }^{3}$ Adam P. Matson, ${ }^{4}$ Ektor T. Rafti, ${ }^{4}$ Linda Guernsey, ${ }^{3}$ \\ Prabitha Natarajan, ${ }^{3}$ Jeffrey T. McNamara, ${ }^{5}$ Craig M. Schramm, ${ }^{4}$ \\ Roger S. Thrall, ${ }^{3}$ and Lawrence K. Silbart ${ }^{6}$ \\ ${ }^{1}$ Helen \& Harry Gray Cancer Center and Department of Medicine, Hartford Hospital, 80 Seymour Street, P.O. Box 5037, \\ Hartford, CT 06102-5037, USA \\ ${ }^{2}$ Department of Medicine, University of CT Health Center (UCHC), Farmington, CT 06030, USA \\ ${ }^{3}$ Department of Immunology, UCHC, Farmington, CT 06030, USA \\ ${ }^{4}$ Department of Pediatrics, UCHC, Farmington, CT 06030, USA \\ ${ }^{5}$ Department of Pathology, UCLA Immunogenetics Center, Los Angeles, CA 90095, USA \\ ${ }^{6}$ Department of Allied Health Sciences, University of CT, Storrs, CT 06268, USA
}

Correspondence should be addressed to Eric R. Secor Jr.; eric.secor@hhchealth.org

Received 17 June 2013; Revised 12 August 2013; Accepted 19 August 2013

Academic Editor: Young-Rae Lee

Copyright (C) 2013 Eric R. Secor Jr. et al. This is an open access article distributed under the Creative Commons Attribution License, which permits unrestricted use, distribution, and reproduction in any medium, provided the original work is properly cited.

\begin{abstract}
The incidence of atopic conditions has increased in industrialized countries. Persisting symptoms and concern for drug side-effects lead patients toward adjunctive treatments such as phytotherapy. Previously, we have shown that Bromelain (sBr), a mixture of cysteine proteases from pineapple, Ananas comosus, inhibits ovalbumin (OVA)-induced murine model of allergic airway disease (AAD). However, sBr's effect on development of AAD when treatment is administered throughout OVA-alum sensitization was unknown and is the aim of the present study. C57BL/6J mice were sensitized with OVA/alum and challenged with 7 days OVA aerosol. $\mathrm{sBr} 6 \mathrm{mg} / \mathrm{kg} / 0.5 \mathrm{ml}$ or PBS vehicle were administered throughout sensitization. Lung, bronchoalveolar lavage (BAL), spleen, and lymph nodes were processed for flow cytometry and OVA-specific IgE was determined via ELISA. sBr treatment throughout OVA-alum sensitization significantly reduced the development of AAD (BAL eosinophils and lymphocytes). OVA-specific IgE and $\mathrm{OVA} \mathrm{TET}^{+}$cells were decreased. $\mathrm{sBr}$ reduced CD1lc ${ }^{+}$dendritic cell subsets, and in vitro treatment of DCs significantly reduced $\mathrm{CD} 44$, a key receptor in both cell trafficking and activation. sBr was shown to reduce allergic sensitization and the generation of AAD upon antigen challenge. These results provide additional insight into sBr's anti-inflammatory and antiallergic properties and rationale for translation into the clinical arena.
\end{abstract}

\section{Introduction}

The incidence of atopic conditions such as asthma, food allergies and atopic dermatitis have increased dramatically in industrialized countries over the last fifty years. Presently, approximately 1 out of 5 Americans suffer from atopic disorders [1], with 1 out of 12 having asthma [2]. Despite major efforts to diagnose and treat these conditions, current conventional medications for allergic disorders are not fully effective. For example, it is estimated that $58 \%$ of primary care patients with asthma have poorly controlled asthma [3].
Poor asthma control may result from inadequate assessment or implementation of asthma therapy by healthcare providers or from poor adherence with prescribed therapy by patients [4]. The persistence of symptoms and disease flares, despite medical therapy and the concern for long-term side effects of corticosteroids [5-8] and long-acting beta- 2 adrenergic agonists [9], have caused many patients to turn to complementary and alternative medicine (CAM) treatments [10]. A review of 17 articles reported that up to $70-80 \%$ of adult asthmatics in the USA use CAM to help control their asthma [11]. Similarly, the reported rates of CAM use in children 
with asthma range from 33 to $89 \%$ (11). In children, the most commonly used CAM therapies are breathing techniques, vitamins, and herbal products or phytotherapy [12].

One such herbal product with demonstrated antiinflammatory efficacy is bromelain. Stem bromelain $(\mathrm{sBr})$ is a mixture of cysteine proteases that is derived from the stem of the pineapple plant, Ananas comosus. Beneficial effects of sBr have been demonstrated in a variety of inflammatory conditions, including rheumatologic diseases in mice and humans [8-13], experimental allergic encephalomyelitis (a murine model of multiple sclerosis) [14], human allergic rhinitis [15], and murine allergic asthma [16]. In an ovalbumin(OVA-) induced asthma model [17], we have shown that sBr administered by either intraperitoneal [16] or oral routes [18] inhibits eosinophilic airway inflammation and allergic airway disease, at least in part via proteolytic cleavage of cell-surface CD25 from activated CD ${ }^{+}$T effector cells [19]. In these experiments, $\mathrm{sBr}$ was administered prior to and during OVA aerosol challenges (but following OVA antigen sensitization). It is noted that $\mathrm{sBr}$ can also affect many other cell surface markers common to T cells and other cell types such as dendritic cells (DC) which could potentially affect their function.

Dendritic cells are professional antigen-presenting cells and are known to take up antigen via specialized endocytic receptors and in response to danger signals and migrate to sites of inflammation [20-22]. Although identifying the specific subsets of DCs which migrate and are responsible for antigen uptake and presentation remains an active area of research, CD44, the receptor for hyaluronic acid, has been shown to be essential for DC migration to regional lymph nodes [23], Th2 skewed T-cell activation [24, 25], and inflammation [26]. Interestingly, sBr has been shown to reduce the expression of CD44 in a variety of models of cell adhesion [27-29] and metastasis [30, 31], thus presenting a plausible mechanism for inhibition of allergic sensitization. Thus, the present study addressed the hypothesis that $\mathrm{sBr}$ could inhibit murine sensitization to OVA via modulation of DCs, which play a key role in allergic sensitization.

\section{Methods}

2.1. Animals. Female C57BL/6J mice, 3-6 months of age, Jackson Laboratory (Bar Harbor, ME), were housed in plastic cages with corncob bedding at $22-24^{\circ} \mathrm{C}$ with a daily light/dark cycle (light from 06:00 to 18:00 h). Chow and water were supplied ad libitum. All protocols were approved by the UConn Animal Care Committee.

2.2. Natural Product Bromelain. For intraperitoneal (i.p.) injections, $60 \mathrm{mg}$ sBr (Vital Nutrients, Middletown, CT) was dissolved in $250 \mathrm{ml}$ PBS. sBr was independently tested for authenticity, potency (2400-2660 GDU g $\left.{ }^{-1}\right)$, and quality as previously described $[16,18,19]$.

2.3. In Vitro Bromelain Studies. $\mathrm{sBr}$ was administered in a dose response manner $(1-100 \mu \mathrm{g} / \mathrm{mL})$ to DCs overnight.
To obtain DCs, spleens of OVA-alum sensitized mice were digested with Collagenase-D (Roche, Indianapolis, IN) $2 \mathrm{mg} / \mathrm{mL}$ for $30 \mathrm{~m}$ at $37^{\circ} \mathrm{C}$, passed through a $40 \mu \mathrm{m}$ nylon cell strainer (BD, Bedford, MA) and erythrocytes lysed with Tris-buffered ammonium chloride at room temperature for $\sim 2$ min. CD1lc $^{+}$cells were then isolated with pan-CD11c microbeads (number 130-092-465; Miltenyi Biotech, Auburn, CA). CD11c $^{+}$cell isolations yielded 3-5 $\times 10^{6}$ cells/spleen with a purity of $>95 \%$. Cells $\left(0.5-1 \times 10^{6}\right)$ were cultured in 24 well plates in $\mathrm{CO}_{2}$ incubator $\left(5 \%, 37^{\circ} \mathrm{C}\right) .100 \mu \mathrm{M}$ E-64 (Sigma, St. Louis, $\mathrm{MO}$ ) was added to neutralize $\mathrm{sBr}$ cysteine protease activity, in selected experiments.

2.4. Bromelain Treatment in OVA-Induced Murine Models of Allergic Airway Disease and OVA/Alum Sensitization. Mice were sensitized with three weekly i.p. or subcutaneous (nape of neck) injections of a suspension containing $25 \mu \mathrm{g}$ of OVA (grade V, Sigma Chemical, St. Louis, MO) and $2 \mathrm{mg}$ of aluminum hydroxide (alum) in $0.5 \mathrm{~mL}$ of saline (Figure 1(a)). OVA-alum was delivered i.p. once per week for 3 consecutive weeks (days $-21,-14$ and -7 ) to C57BL/6J mice (Figure 1(b)) PBS or sBr was delivered i.p. (6 mg/kg in $0.5 \mathrm{ml} \mathrm{PBS}$ ) twice daily, $M-F$ throughout sensitization. In prior studies we determined that $\mathrm{sBr}(6 \mathrm{mg} / \mathrm{kg}$ in PBS $)$ administered i.p. twice daily for 3 consecutive weeks caused no significant elevation in liver enzymes or BAL protein in these animals (see Supplemental Table 1 in Supplementary Materials available at http://dx.doi.org/10.1155/2013/702196).

After sensitization, animals were rested for 1 week and then challenged with $1 \%$ aerosolized OVA in $0.9 \%$ saline, $1 \mathrm{~h}$ per day, for seven days (days $0-7),[16,19]$. Twenty-four hours after the final aerosol exposure, the mice were sacrificed by drug overdose $(0.15 \mathrm{~mL}$ i.p. injection per $20 \mathrm{~g}$ mouse of $13 \mathrm{mg}$ Ketamine HCL, Ketaset-III For Dodge Animal Health, Fort Dodge, IA, USA, and $0.4 \mathrm{mg}$ of xylazine, Tranquived Vedco, St. Joseph, MO, USA) and exsanguination.

Animals were also sacrificed 24 hours after each weekly sensitization (Figure 1(b)); S1 (week 1), S2 (week 2), and S3 (week 3), and tissues (spleen, lymph nodes, and BAL) were processed for assessment of the antigen-specific responses. In selected experiments, a group of mice treated with E64inhibited-sBr was added as a control for the cysteine protease activity of $\mathrm{sBr}$. The $\mathrm{sBr}$ dosages used were based on prior in vivo and in vitro dose response studies performed in our laboratory $[16,18,19]$.

2.5. BAL Cellular Analysis. Lungs were lavaged in situ with five $1 \mathrm{~mL}$ aliquots of $0.9 \%$ saline. BAL fluid was centrifuged $(200 \mathrm{~g} \times 10 \mathrm{~min})$, the pellet was resuspended in saline, and total nucleated cells were counted with a hemocytometer using Nigrosin exclusion for viability. Leukocyte differentials were determined using cytocentrifuged (at $900 \mathrm{rpm}$ for 5 min, Thermo Scientific Shandon Cytospin-4, Leicestershire, England, UK) preparations stained with May-Grünwald and Giemsa (Accustain, Sigma, St Louis, MO, USA). The remaining cells were analyzed phenotypically for T-cell subpopulations by flow cytometry. 


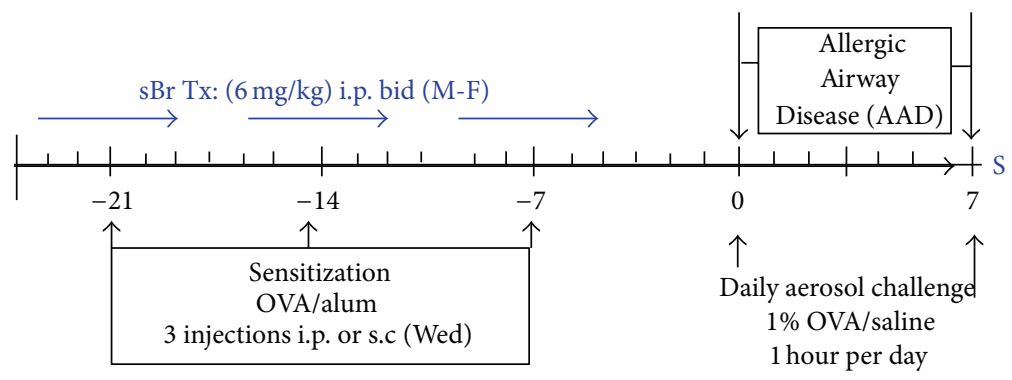

(a)

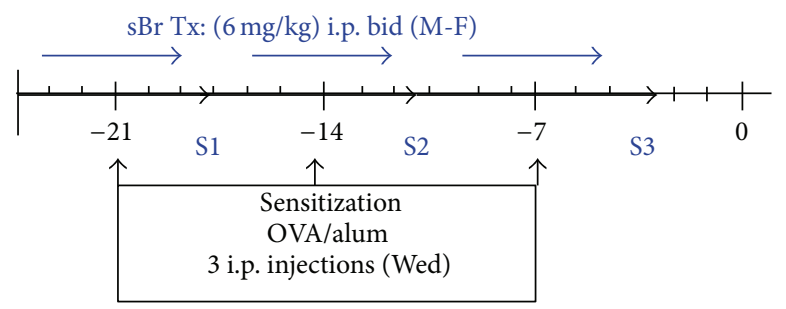

(b)

FIGURE 1: Protocols for sBr treatment in murine models of allergic airway disease. (a) Mice ( $n=8-10$ per group) were sensitized to OVA-alum (i.p.) weekly, for 3 consecutive weeks. $\mathrm{sBr}(6 \mathrm{mg} / \mathrm{kg}$ in $0.5 \mathrm{ml} \mathrm{PBS})$ or PBS was delivered i.p. twice daily. On day 0 , mice were challenged with OVA aerosol for seven consecutive days and sacrificed (S) 24 hours later. (b) Sensitization and i.p. sBr treatment were the same as in (a). Animals were sacrificed $24 \mathrm{hrs}$ after each week or treatment; S1 (week 1), S2 (week 2), and S3 (week 3). In selected experiments groups of mice were treated with E64-inhibited-sBr.

2.6. Flow Cytometry. Cells for analysis via fluorescenceactivated cell sorting (FACS) were obtained from BAL, homogenized lung tissue, spleen, and lymph nodes. BAL samples were washed in PBS (Dulbecco's Phosphate Buffered Saline, pH 7.4, Sigma, St Louis, MO, USA) and tissues processed and labeled with monoclonal antibodies in standard manner for flow cytometry. The following monoclonal antibodies were used for cellular surface staining: $\alpha$-CD3 (145-2c11), CD4 (RM4-5), CD8 (53-6.72), $\alpha$ CD11a (2D7), CD44 (IM7), $\alpha$-CD62L (MEL-14), CD86 (GL1), CD11b (M1/70), CD103 (2E7), CD11c (N418), F4/80 (BM8), and MHCII (M5/114.15.2) and were purchased from eBioscience (San Diego, CA) or BioLegend (San Diego, CA). $\mathrm{H}-2 \mathrm{~K}^{\mathrm{b}}$ tetramers containing the OVA-derived peptide SIINFEKL were generated in the laboratory as described previously [32]. Enrichment of OVA-TET ${ }^{+} \mathrm{CD}^{+} \mathrm{T}$ cells from mice was accomplished by processing single cell suspensions from the spleen or pooled lymph nodes (axillary, mandibular, cervical, HLN, ILN, colic, jejunal, and caudal mesenteric). Cells were then stained with both phosphatidylethanolamine- and allophycocyanin (APC)labeled tetramers and $\alpha$-CD 8 antibody then counter-stained with $\alpha$-phosphatidylethanolamine microbeads as per the instructions of the manufacturer (Miltenyi Biotec, Auburn, CA). Samples were then run on an AutoMACs (Miltenyi Biotec) magnetic column cell separator. After enrichment, cells were stained with $\alpha$-CD11a, $\alpha$-CD62L, $\alpha-\mathrm{CD} 4, \alpha-\mathrm{IA}^{\mathrm{b}}$, and $\alpha$-CD11b for 30 minutes at $4^{\circ} \mathrm{C}$. Cells were then washed and fixed with $2 \%$ paraformaldehyde. Cell samples were acquired with an LSRII cytometer (Becton Dickinson Biosciences, San Jose, CA) and analyzed with FlowJo software
(Tree Star, Inc., Ashland, OR). General gating strategies are depicted in Supplementary Figure 3.

2.7. Statistical Analysis. Statistical comparisons between groups were made with analysis of variance and unpaired $t$-tests using JMP Software (SAS Institute Inc., Cary, NC, USA). All data were expressed as means \pm standard error of the mean, and differences were considered significant at $P \leq 0.05$.

\section{Results}

3.1. Bromelain Administration during Sensitization Prevented Development of Allergic Airway Disease. In the current studies, treatment of mice with bromelain during the sensitization prevented the development of AAD in the animals (Figure 2). Total BAL leukocytes were markedly reduced in sBr-treated AAD mice as compared to control AAD animals (PBS controls $683.8 \pm 120 \times 10^{4} ; \mathrm{sBr} 58.1 \pm 16.7 \times 10^{4}$ cells; $P<$ 0.0001 ; Figure 2(a)). In regards to the BAL WBC differentials (Figure 2(b)), MACs remained prevalent with sBr treatment (PBS treated $8.0 \pm 1 \%$; sBr $92 \pm 4 \%$ ); $P<0.0001$ ), lymphs (PBS treated $11.9 \pm 1.7 \%$; sBr $3.3 \pm 1.8 \% ; P<0.0001$ ), and EOS (PBS treated $78.5 \pm 2.8 \%$; sBr $4.3 \pm 3 \%$; $P<0.0001$ ) were significantly reduced and PMNs (PBS treated $1.6 \pm 1 \%$; sBr $0 \pm$ $0 \%)$ remained unchanged.

Similar effects were observed in the OVA-alum subcutaneously sensitized mice, with i.p administration of sBr (Supplementary Figure 4). sBr decreased total BAL leukocytes (PSB control $64 \pm 8 \times 10^{5}, \mathrm{sBr} 18 \pm 4 \times 10^{5} ; P<0.001$ ) as well as BAL eosinophils (PSB control $56 \pm 8 \times 10^{5}$, sBr $14 \pm 3 \times 10^{5}$; 


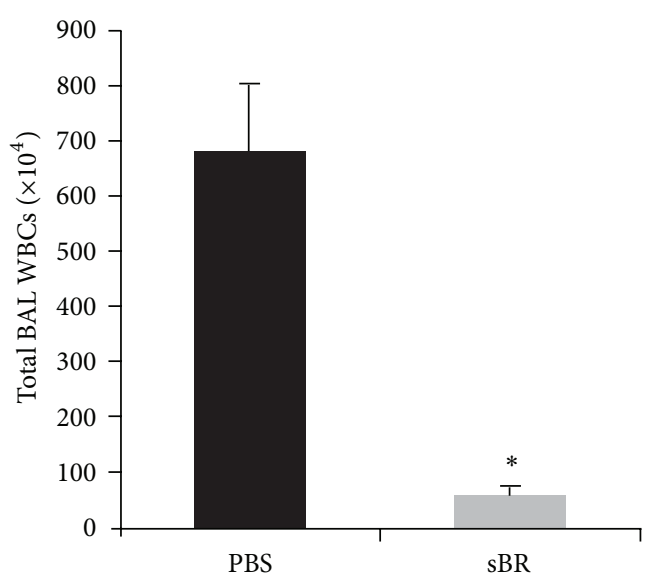

(a)

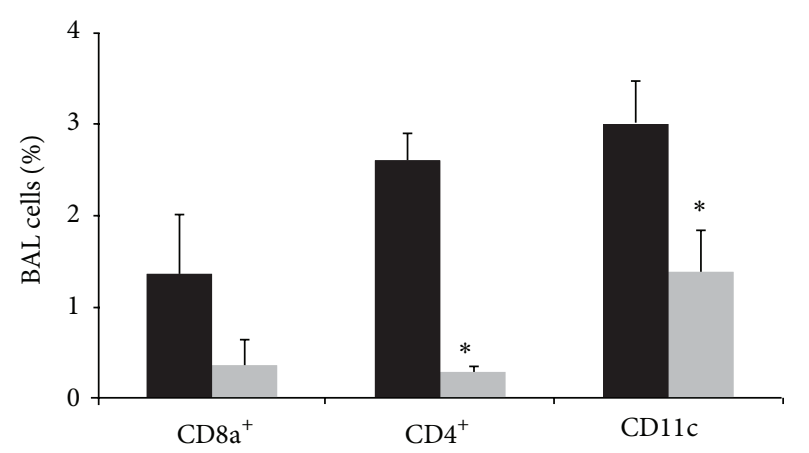

- PBS

- $\mathrm{sBr}$

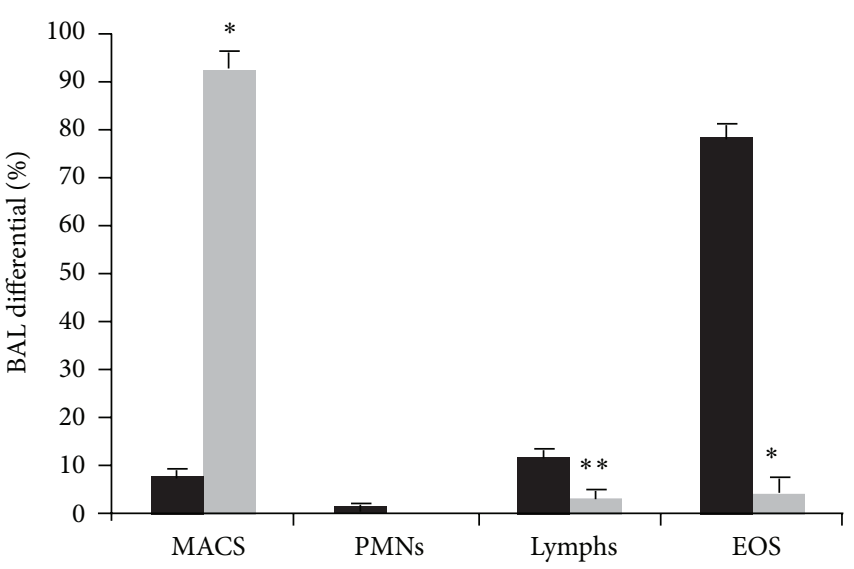

(b)

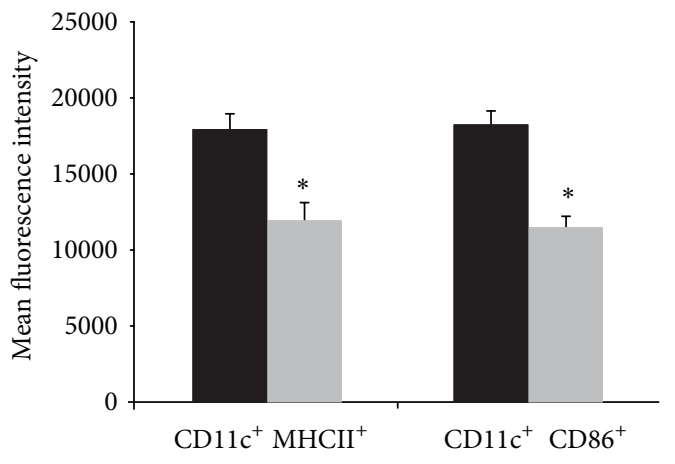

a PBS

- $\mathrm{sBr}$

(c)

(d)

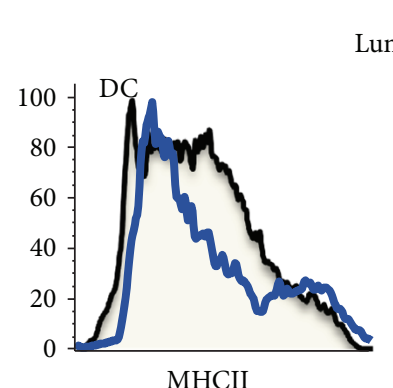

ung
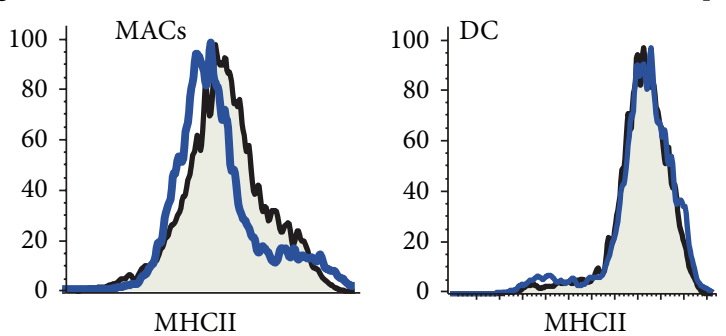

Spleen
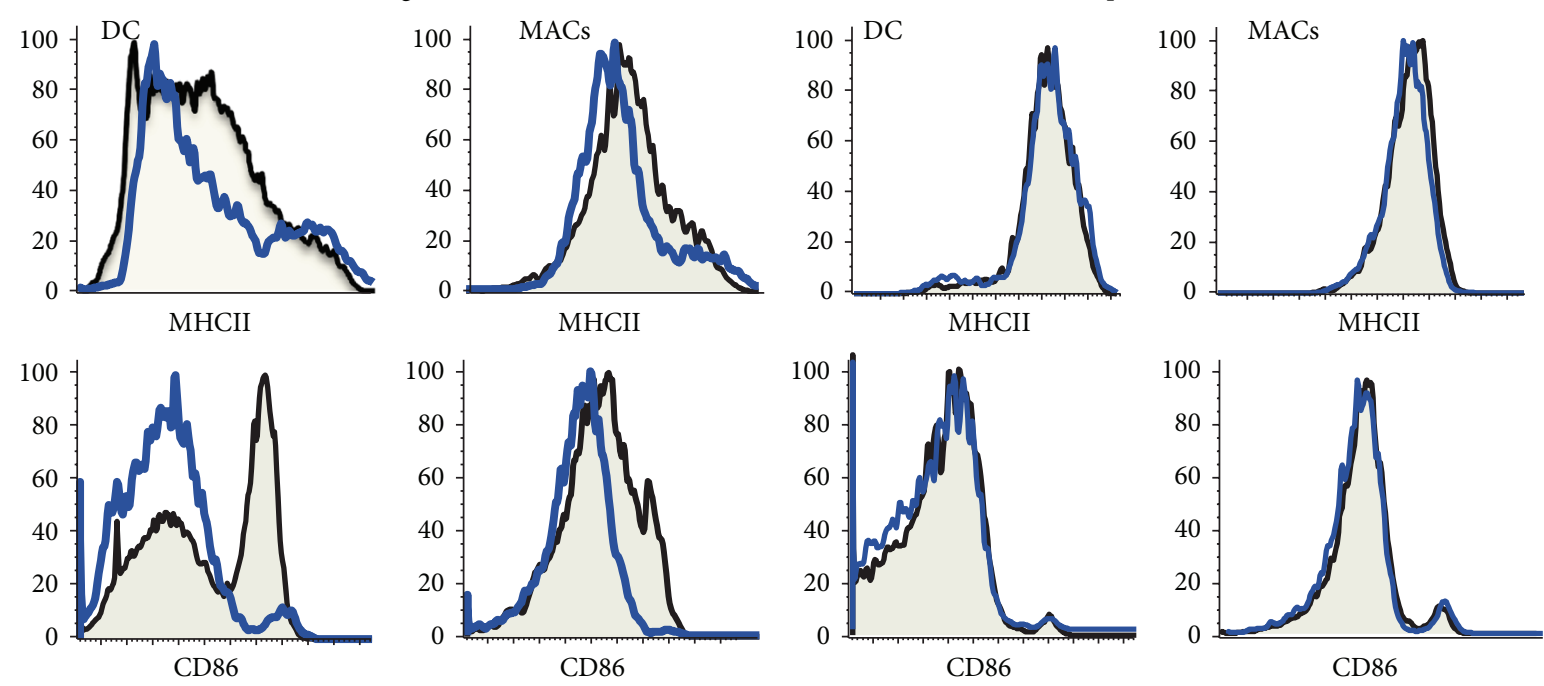

ㅁ $\mathrm{PBS}$

(e)

FIGURE 2: Bromelain treatment through sensitization abrogates the development of AAD upon OVA aerosol challenge. As compared to PBS treated controls, sBr treatment significantly reduced total BAL WBCs (a) as well as lymphocytes and eosinophils (b). sBr also inhibited influx of $\mathrm{BAL} \mathrm{CD}^{+}$and $\mathrm{CD}^{+} \mathrm{T}$ lymphocytes and $\%$ of $\mathrm{CD}_{11 \mathrm{c}^{+}}$cells and mean fluorescent intensity of CD86 and MHCII (c). A representative FACS plot (e) compares the MHCII and CD86 expression on lung DCs $\left(\mathrm{CD} 11 \mathrm{c}^{+} \mathrm{F} 480^{-}\right)$and MACs $\left(\mathrm{CD} 11 \mathrm{c}^{+} \mathrm{F} 480^{+}\right)$with those in the spleen $(n=8-10$ per group). 
$P<0.001), n=8$ animals per group. These observations confirmed that the inhibitory effect of i.p. sBr was not due to allosteric interaction with the i.p. OVA.

\subsection{Bromelain Administration during Sensitization Reduced} Regional Lymphocytes and Cell Activation after OVA Aerosol Challenge. The above BAL differentials showed that the inhibition of allergic airway disease by sBr treatment was accompanied by an absence of airway lymphocytosis in treated animals. Subsequent FACS analysis demonstrated marked reductions in BAL CD4 ${ }^{+}$and $\mathrm{CD} 8^{+} \mathrm{T}$ cells as well as $\mathrm{CD} 11 \mathrm{c}^{+}$ cells in sBr-treated animals (Figure 2(c)). Accompanying the regional reduction in T-cell numbers, the mean fluorescence intensity (MFI) of activation markers MHCII and CD86 were significantly reduced on $\mathrm{CD}_{11 c^{+}} \mathrm{DCs}$ in lung tissue of sBr-treated mice (Figure 2(d)). A representative histogram (Figure 2(e)) demonstrates that this reduction in receptor expression was predominant in $\mathrm{CD} 11 \mathrm{c}^{+} \mathrm{F} 4 / 80^{-}$DCs localized to the lung tissue as compared to the spleen.

\subsection{Bromelain Administration during Sensitization Inhibited} Antigen-Specific Immunoglobulin Production. The prevention of AAD in mice treated with bromelain during OVA sensitization suggested that bromelain interfered with the sensitization process. This consideration was first addressed by measurement of OVA-specific IgE levels after each of the OVA-alum injections. As expected, i.p. sensitization with OVA-alum resulted in the production of OVA-specific IgE. Serum OVA-specific IgE levels increased from nondetectable levels in naïve animals to $869 \pm 379 \mathrm{ng} / \mathrm{mL}$ following the third i.p. injection (Figure 3). This increase was markedly inhibited in sBr-treated animals, with a final $\operatorname{IgE}$ level of only $71 \pm 37 \mathrm{ng} / \mathrm{mL}$. The attenuation was due to the proteolytic action of $\mathrm{sBr}$, since treatment of $\mathrm{sBr}$ with the antiprotease E64 abolished the effect. Mice treated with E64-treated sBr developed OVA-specific IgE levels of $1165 \pm$ $461 \mathrm{ng} / \mathrm{mL}$ after the third i.p sensitization.

\subsection{Bromelain Treatment throughout Sensitization Prevented} Generation of an OVA Specific CD $8^{+}$T-Cell Response. As in Figure 1(b) Protocol-, PBS-, or sBr-treated animals were sacrificed after each weekly OVA-alum i.p. Spleen and nodes (mediastinal, cervical, axillary, brachial, inguinal, and mesenteric) were pooled and enriched for OVA-specific $\mathrm{CD}^{+}$ $\mathrm{T}$ cells via SIINFEKL $\left(\mathrm{OVA}_{257-264}\right)$ loaded tetramer. As compared to PBS-treated controls, $\mathrm{sBr}$ treatment significantly limited the expansion of total OVA-TET ${ }^{+} \mathrm{CD}^{+} \mathrm{T}$ cells after each weekly OVA-alum i.p. (Figure 4).

3.5. Bromelain Administration during OVA-Alum Sensitization Reduced DCs in the MLNs. The attenuation of both IgE and T-cell responses to OVA demonstrated that $\mathrm{sBr}$ modulated pathways involved in allergic sensitization. One key pathway involves antigen presentation by DCs; therefore, we wanted to determine if $\mathrm{sBr}$ altered DCs after sensitization. As in Figure 1(b), sBr was administered throughout the 1st OVA-alum i.p., and DCs subtypes were evaluated in the spleen and MLNs. sBr did not affect the number of splenic

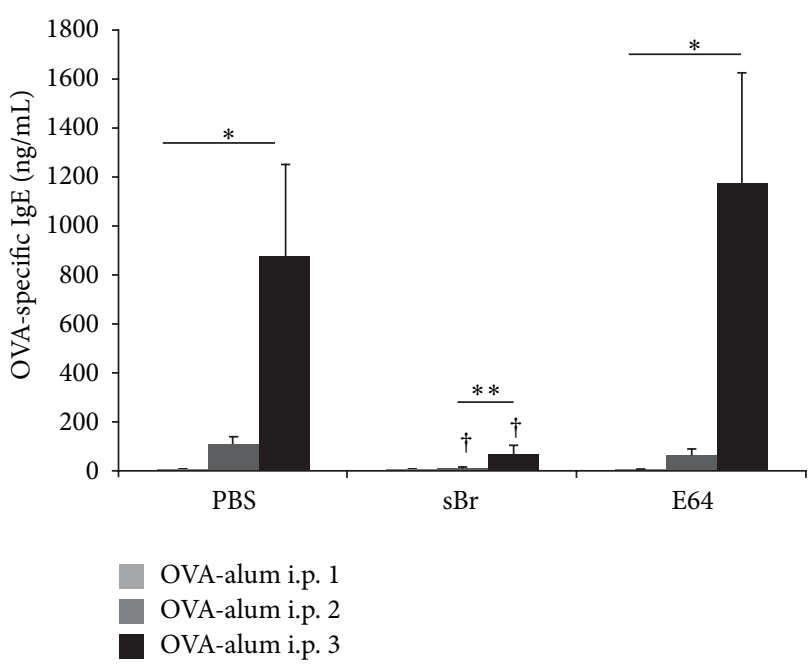

FIGURE 3: sBr treatment throughout sensitization reduces production of antigen-specific IgE. Peripheral blood of mice (PBS, sBr, or E64-inhibited-sBr) was collected after each weekly sensitization and serum was processed for concentration of OVA-specific IgE. In PBStreated controls, a significant increase in the concentration of OVAspecific IgE was noted after i.p.s 2 and 3 when compared to i.p. 1 . In sBr-treated groups, the production OVA-specific IgE was delayed and attenuated relative to PBS groups. IgE production was restored in the E64 treatment group. PBS: phosphate buffered saline, E64: E64-inhibited-sBr $\left({ }^{*} P<0.001,{ }^{* *} P<0.05\right.$ between i.p.'s; ${ }^{\dagger} P<0.01$ between PBS treated groups; $n=4$ per group).

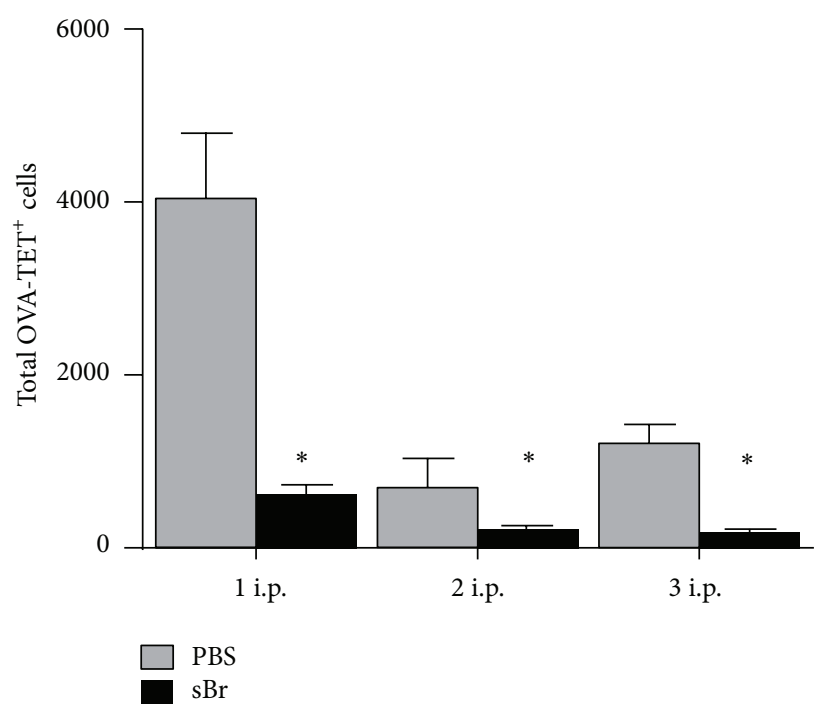

FIGURE 4: sBr treatment throughout sensitization prevents generation of OVA-specific $\mathrm{CD} 8^{+} \mathrm{T}$-cell response. Animals were sacrificed after each weekly OVA-alum i.p. Spleen and nodes were pooled and enriched for OVA-specific $\mathrm{CD}^{+}{ }^{+}$T cells via SIINFEKL (OVA $257-264$ ) loaded tetramer. As compared to PBS-treated controls, sBr treatment significantly limited the expansion of total OVA-TET ${ }^{+} \mathrm{CD}^{+}$ T cells after each weekly OVA-alum i.p. $\left({ }^{*} P<0.001\right.$ compared to PBS; $n=3-5$ per group). 


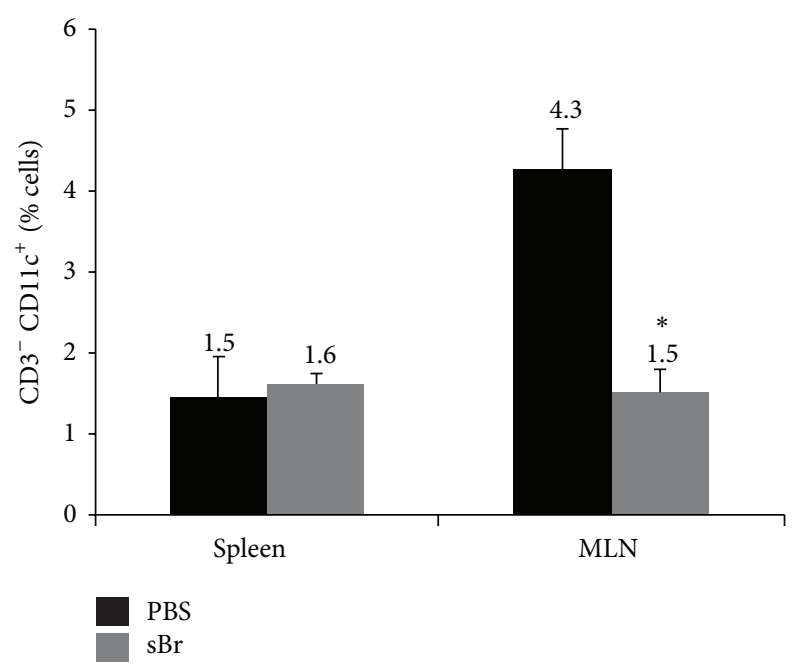

(a)

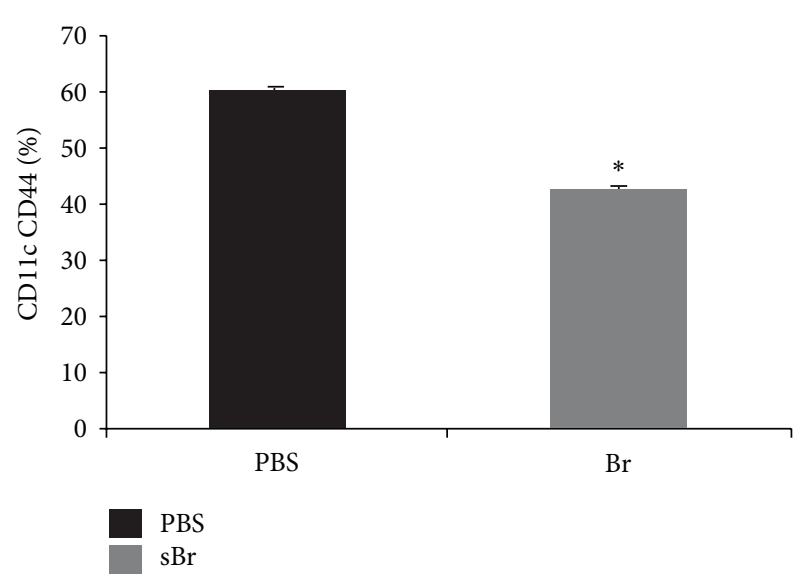

(b)

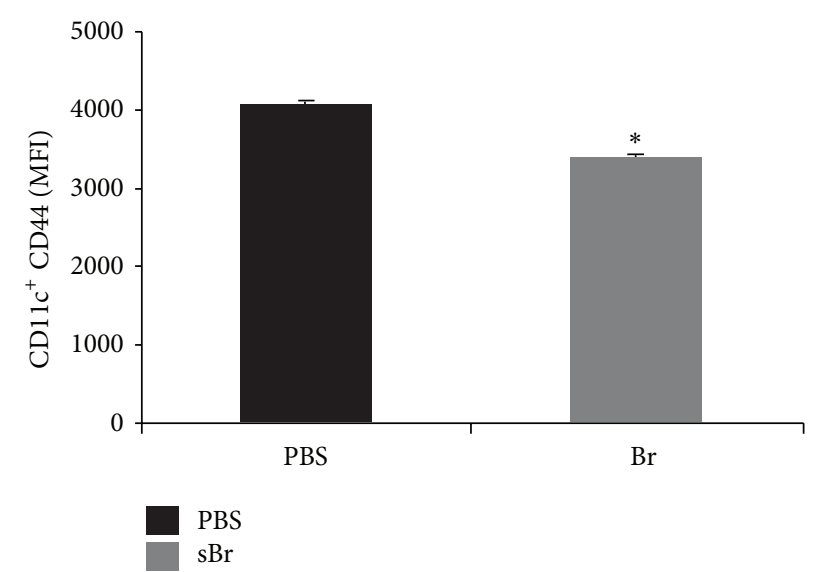

(c)

FIGURE 5: sBr treatment through OVA/alum sensitization reduces DCs in the MLN. Animals were treated with sBr and PBS through the first OVA-alum i.p. Upon sacrifice spleen, and pooled MLN (mesenteric lymph nodes) were processed for analysis via flow cytometry. CD3 ${ }^{-}$ $\mathrm{CD}_{11 c^{+}}$DCs were reduced in MLNs in sBr-treated animals as compared to PBS-treated controls. Both the percentage of CD44 ${ }^{+}$cells (b) and the mean fluorescent intensity (MFI) of CD44 (c) were significantly reduced in the sBr treatment group as compared to the control PBS group. ${ }^{*} P<0.05 ; n=5$ animals per group.

DCs in OVA-sensitized mice, as assessed by percentage of $\mathrm{CD}_{11 c^{+}}$cells. However, the percentage of DCs in the MLNs was significantly reduced (Figure $5(\mathrm{a})$ ) by sBr administration (PBS $4.3 \pm 0.5 \%$, sBr $1.5 \pm 0.2 \% ; P<0.0001$ ). Both the percentage (Figure 5(b)) and MFI of CD44 were significantly reduced in vivo. In addition, the total $\mathrm{CD}_{11 c^{+}}$cells were reduced in the MLN in CD103 (Supplementary Figure 4(a)), $\mathrm{CDllb}^{+} \mathrm{CD}^{+}$(Supplementary Figure 4(b)) and $\mathrm{CDIlb}^{-} \mathrm{CD}^{+}$ (Supplementary Figure 4(c)) subsets.

3.6. In Vitro $\mathrm{sBr}$ Treatment of DCs Reduced CD44. Noting that there was a reduction in DCs in the MLNs in addition to $\mathrm{CD} 44$ expression with in vivo $\mathrm{sBr}$ treatment, we wanted to confirm in vitro that $\mathrm{sBr}$ was having specific effect on DC receptor expression. Therefore, $\mathrm{CD} 1 \mathrm{c}^{+} \mathrm{DCs}$ were isolated via positive selection with pan CD11c microbeads and cultured overnight with escalating doses of $\mathrm{sBr}(1-100 \mu \mathrm{g} / \mathrm{mL})$ and
$100 \mu \mathrm{M}$ E-64 inhibited sBr $100 \mu \mathrm{g} / \mathrm{mL}$ (Figure 6). As compared to cells in media alone, $\mathrm{sBr}$ treatment did not alter the expression of CD11c or MHCII (data not shown). However, CD44 expression was reduced by $\mathrm{sBr}$ at doses of $5 \mu \mathrm{g} / \mathrm{mL}$ and greater (Figure 6(b)), with similar reductions in CD44 noted between the 5 and $100 \mu \mathrm{g} / \mathrm{mL}$ doses (Figure 6(c)).

\section{Discussion}

In previous studies, we demonstrated that i.p. or oral administration of $\mathrm{sBr}$ before, during, or after antigen challenge blunts the development of AAD in previously OVA-sensitized mice $[16,18,19]$. The present study extended those findings to demonstrate that $\mathrm{sBr}$ given during the sensitization markedly diminished the AAD response to subsequent aerosolized OVA challenge ( $\sim 90 \%)$, despite the absence of $\mathrm{sBr}$ treatment during the aerosol challenge period. The BAL of naïve mice 


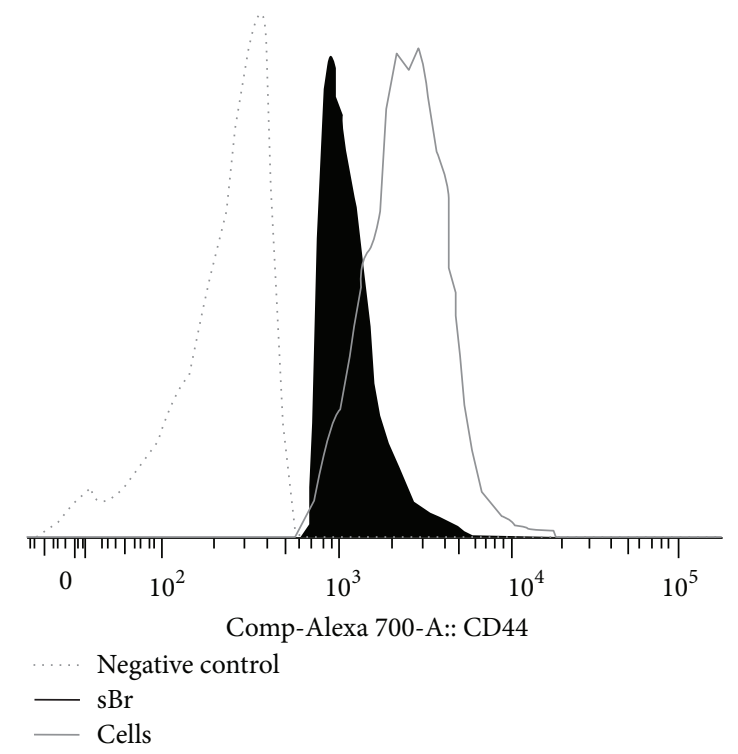

(a)

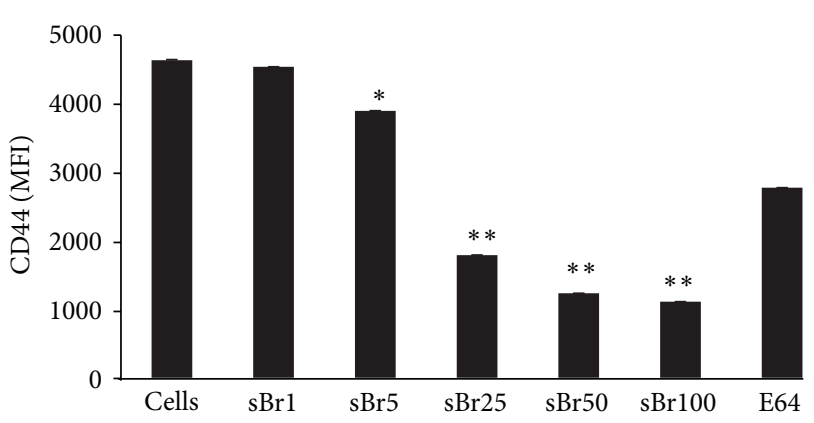

(b)

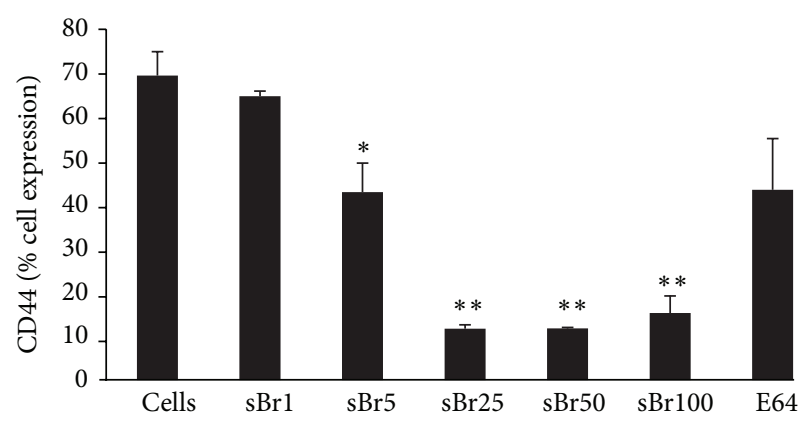

(c)

FIGURE 6: $\mathrm{sBr}$ treatment of DCs in vitro results in reduced expression of CD44. MLN DCs were selected using Pan DC Beads and cells (5 $\times 10^{5} /$ well) were cultured overnight. (a) Representative histogram of CD44 expression on cells in media alone (MFI 2668), sBr $100 \mu \mathrm{g} / \mathrm{mL}$ treated cells MFI (1198), and negative control (MFI 244). (b) denotes MFI of CD44 and (c) \% cell expression of CD44 on cells alone, sBr $(1-100 \mu \mathrm{g} / \mathrm{mL})$, and (E64 treated sBr $100 \mu \mathrm{g} / \mathrm{mL})$. Gates were on live, $\mathrm{CD}^{-} \mathrm{CD} 1 \mathrm{c}^{+} \mathrm{MHCII}^{+}$cells; MFI: mean fluorescence intensity. ${ }^{*} \mathrm{P}<$ $0.01 ;{ }^{* *} P<0.0001$ as compared to control cells in media alone. Data represents triplicate wells of duplicate experiments. and mice undergoing OVA sensitization but no OVA-aerosol challenge consists of $>95 \%$ macrophages with minimal presence of other cell types [19]. This differential distribution of BAL cell types was not affected during the 3 weeks of sensitization by concomitant administration of sBr (Supplementary Figure 1). In contrast, allergic airway disease (AAD), induced by 3-10 days of aerosolized OVA challenges to sensitized mice, is characterized by marked elevations in eosinophils and lymphocytes [19]. sBr exerted profound inhibitory effects on OVA sensitization itself, resulting in marked reductions in serum OVA-specific IgE and generation of OVA-TET ${ }^{+} \mathrm{CD}^{+}$ $\mathrm{T}$ cells. The lack of allergic sensitization was accompanied by a reduction in DCs in the MLN, the percentage of CD $44^{+}$cells, and a reduction in expression of CD44, a key modulator of DC activation and migration, in vitro.

CD44 is one of the most sensitive surface markers to bromelain degradation. The $\sim 80 \%$ reduction in CD44 expression with sBr treatment noted in these in vitro studies is similar to the $>90 \%$ reduction reported by Hale and colleagues in CD44 levels in human peripheral blood lymphocytes incubated for 1 hour in the presence of $\mathrm{sBr}$ [27]. CD44 is involved in a number of important biological processes including lymphocyte activation and homing, hematopoiesis, and tumor progression, and metastasis [30]. Of particular relevance to allergies and asthma, it has been shown that CD44 expression on DCs plays a crucial role in DC activation of $\mathrm{T}$ cells. The engagement of CD44 molecules expressed on the surface of DCs by specific mAbs or by its extracelluar matrix ligand, hyaluronic acid, induces DC phenotypic and functional maturation [31]. This maturation is associated with increased expression of several surface markers, including HLA class II molecules, and increased allogeneic T cell stimulatory capacity [33-35]. CD44 receptor activity is induced by antigen stimulation in antigen-sensitized spleen $\mathrm{CD} 4^{+} \mathrm{T}$ cells, and T-cell expression of CD44 is important for the accumulation of antigen-specific Th2 cells in the airway and in the development of AAD induced by antigen challenge $[32,36]$. Thus, sBr-induced reduction of CD44 on DCs could have resulted in impaired sensitization to antigen. Future studies will investigate the role of $\mathrm{sBr}$ on antigen uptake and presentation in DCs to determine the degree to which DC function is altered.

In summary, the present study demonstrated that $\mathrm{sBr}$ attenuated the $\mathrm{AAD}$ response when administered throughout sensitization. Additionally, sBr prevented allergic sensitization, which was attributed to reduced accumulation of DCs in the MLNs and decreased CD44 expression of treated DCs in vitro. Future research may confirm sBr's role and the specific components within $\mathrm{sBr}$ [37] which modulate antigen uptake and presentation in DCs. Both pathways are likely targets in combating allergies. These findings identified an additional inhibitory mechanism of $\mathrm{sBr}$ on allergic responses and further support the potential utility of this CAM product in the treatment of allergies and asthma.

\section{Conflict of Interests}

The authors have no conflict of interests. 


\section{Authors Contributions}

Drs. Szczepanek, Linda Guernsey, Christine Castater, and Prabitha Natarajan assisted with animal experiments, acquisition of data, and its analysis and interpretation. Drs. Adam P. Matson and Ektor T. Rafti processed animal samples for acquisition of OVA-specific immunoglobulin data as well as analysis and interpretation. Dr. McNamara assisted with OVA-tetramer studies. Drs. Schramm, Thrall, and Silbart participated in adding substantial intellectual content, study design, and helping in original drafting and revising of the paper. The authors also provided comments and suggestions with the paper content.

\section{Acknowledgments}

The authors would like to thank Dr. Enrico Liva of Vital Nutrients, Middletown CT, for providing Bromelain quality control data and Dr. Anurag Singh (Nestlé Research Center, Lausanne, Switzerland) for intellectual contributions during the initiation of this research project.

\section{References}

[1] Asthma and Allergy Foundation of America, "Asthma facts and figures," February 2012, http://www.aafa.org/display.cfm?id= $8 \&$ sub=42\#_ftnref1.

[2] Centers for Disease Control and Prevention, "Asthma in the US,” CDC Vital Signs, May 2011, http://www.cdc.gov/vitalsigns/Asthma/.

[3] M. Mintz, A. W. Gilsenan, C. L. Bui et al., "Assessment of asthma control in primary care," Current Medical Research and Opinion, vol. 25, no. 10, pp. 2523-2531, 2009.

[4] P. Barnes, "Achieving asthma control," Current Medical Research and Opinion, vol. 21, supplement 4, pp. S5-S9, 2005.

[5] L.-P. Boulet, "Perception of the role and potential side effects of inhaled corticosteroids among asthmatic patients," Chest, vol. 113, no. 3, pp. 587-591, 1998.

[6] V. Cooper, L. Metcalf, J. Upton, S. Walker, J. Versnel, and R. Horne, "Concerns about corticosteroids among people with asthma: implications for clinical interventions," Thorax, vol. 65, supplement 4, article A83, 2010.

[7] N. A. Hanania, K. R. Chapman, W. C. Sturtridge, J. P. Szalai, and S. Kesten, "Dose-related decrease in bone density among asthmatic patients treated with inhaled corticosteroids," Journal of Allergy and Clinical Immunology, vol. 96, no. 5, pp. 571-579, 1995.

[8] P. J. Sharek and D. A. Bergman, "The effect of inhaled steroids on the linear growth of children with asthma: a meta-analysis," Pediatrics, vol. 106, no. 1, p. e8, 2000.

[9] U. S. Food and Drug Administration, "FDA Drug Safety Communication: new safety requirements for long-acting inhaled asthma medications called Long-Acting BetaAgonists (LABAs)," February 2010, http://www.fda.gov/Drugs/ DrugSafety/.

[10] D. H. Kopnina, “Contesting asthma medication: patients' view of alternatives," Journal of Asthma, vol. 47, no. 6, pp. 687-694, 2010.

[11] C. A. Slader, H. K. Reddel, C. R. Jenkins, C. L. Armour, and S. Z. Bosnic-Anticevich, "Complementary and alternative medicine use in asthma: who is using what?" Respirology, vol. 11, no. 4, pp. 373-387, 2006.

[12] J. Shen and E. Oraka, "Complementary and Alternative Medicine (CAM) use among children with current asthma," Preventive Medicine, vol. 54, no. 1, pp. 27-31, 2012.

[13] A. Wittenborg, P. R. Bock, J. Hanisch, R. Saller, and B. Schneider, "Comparative epidemiological study in patients with rheumatic diseases illustrated in an example of a treatment with nonsteroidal anti-inflammatory drugs versus an oral enzyme combination," Arzneimittel-Forschung, vol. 50, no. 8, pp. 728-738, 2000.

[14] O. S. Targoni, M. Tary-Lehmann, and P. V. Lehmann, "Prevention of murine EAE by oral hydrolytic enzyme treatment," Journal of Autoimmunity, vol. 12, no. 3, pp. 191-198, 1999.

[15] R. Guo, P. H. Canter, and E. Ernst, "Herbal medicines for the treatment of rhinosinusitis: a systematic review," Otolaryngology, vol. 135, no. 4, pp. 496-506, 2006.

[16] E. R. Secor Jr., W. F. Carson IV, M. M. Cloutier et al., "Bromelain exerts anti-inflammatory effects in an ovalbumin-induced murine model of allergic airway disease," Cellular Immunology, vol. 237, no. 1, pp. 68-75, 2005.

[17] C. A. Yiamouyiannis, C. M. Schramm, L. Puddington et al., "Shifts in lung lymphocyte profiles correlate with the sequential development of acute allergic and chronic tolerant stages in a murine asthma model," American Journal of Pathology, vol. 154, no. 6, pp. 1911-1921, 1999.

[18] E. R. Secor Jr., W. F. Carson IV, A. Singh et al., "Oral bromelain attenuates inflammation in an ovalbumin-induced murine model of asthma," Evidence-based Complementary and Alternative Medicine, vol. 5, no. 1, pp. 61-69, 2008.

[19] E. R. Secor Jr., A. Singh, L. A. Guernsey et al., "Bromelain treatment reduces $\mathrm{CD} 25$ expression on activated $\mathrm{CD} 4^{+} \mathrm{T}$ cells in vitro," International Immunopharmacology, vol. 9, no. 3, pp. 340-346, 2009.

[20] Y. Do, A. M. Didierlaurent, S. Ryu et al., "Steinman RM Induction of pulmonary mucosal immune responses with a protein vaccine targeted to the DEC-205/CD205 receptor," Vaccine, vol. 30, no. 45, pp. 6359-6367, 2012.

[21] C. G. Park and A. Rodriguez, "Steinman RM PE-Cy5.5 conjugates bind to the cells expressing mouse DEC205/CD205," Journal of Immunological Methods, vol. 384, no. 1-2, pp. 184-190, 2012.

[22] T. Fukaya, R. Murakami, H. Takagi et al., "Conditional ablation of $\mathrm{CD}_{205^{+}}$conventional dendritic cells impacts the regulation of T-cell immunity and homeostasis in vivo," Proceedings of the National Academy of Sciences of the United States of America, vol. 109, no. 28, pp. 11288-11293, 2012.

[23] J. M. Weiss, A. C. Renkl, J. Sleeman et al., "CD44 variant isoforms are essential for the function of epidermal langerhans cells and dendritic cells," Cell Communication and Adhesion, vol. 6, no. 2-3, pp. 157-160, 1998.

[24] V. L. Hegde, N. P. Singh, P. S. Nagarkatti, and M. Nagarkatti, "CD44 mobilization in allogeneic dendritic cell-T cell immunological synapse plays a key role in T cell activation," Journal of Leukocyte Biology, vol. 84, no. 1, pp. 134-142, 2008.

[25] M. H. Siegelman, H. C. DeGrendele, and P. Estess, "Activation and interaction of CD44 and hyaluronan in immunological systems," Journal of Leukocyte Biology, vol. 66, no. 2, pp. 315321, 1999.

[26] K. Gee, M. Kryworuchko, and A. Kumar, "Recent advances in the regulation of $\mathrm{CD} 44$ expression and its role in inflammation 
and autoimmune diseases," Archivum Immunologiae et Therapiae Experimentalis, vol. 52, no. 1, pp. 13-26, 2004.

[27] L. P. Hale, P. K. Greer, and G. D. Sempowski, "Bromelain treatment alters leukocyte expression of cell surface molecules involved in cellular adhesion and activation," Clinical Immunology, vol. 104, no. 2, pp. 183-190, 2002.

[28] T. Harrach, F. Gebauer, K. Eckert, R. Kunze, and H. R. Maurer, "Bromelain proteinases modulate the CD44 expression on human Molt 4/8 leukemia and SK-Mel 28 melanoma cells in vitro," International Journal of Oncology, vol. 5, no. 3, pp. 485488, 1994.

[29] E. Munzig, K. Eckert, T. Harrach, H. Graf, and H. R. Maurer, "Bromelain protease $\mathrm{F} 9$ reduces the $\mathrm{CD} 44$ mediated adhesion of human peripheral blood lymphocytes to human umbilical vein endothelial cells," FEBS Letters, vol. 351, no. 2, pp. 215-218, 1994.

[30] E. Grabowska, K. Eckert, I. Fichtner, K. Schulze-Forster, and H. R. Maurer, "Bromelain proteases suppress growth, invasion and lung metastasis of B16F10 mouse melanoma cells," International Journal of Oncology, vol. 11, no. 2, pp. 243-248, 1997.

[31] H. Ponta, L. Sherman, and P. A. Herrlich, "CD44: from adhesion molecules to signalling regulators," Nature Reviews Molecular Cell Biology, vol. 4, no. 1, pp. 33-45, 2003.

[32] S. Katoh, S. Maeda, H. Fukuoka et al., "A crucial role of sialidase Neul in hyaluronan receptor function of CD44 in T helper type 2-mediated airway inflammation of murine acute asthmatic model," Clinical and Experimental Immunology, vol. 161, no. 2, pp. 233-241, 2010.

[33] V. L. Hegde, N. P. Singh, P. S. Nagarkatti, and M. Nagarkatti, "CD44 mobilization in allogeneic dendritic cell-T cell immunological synapse plays a key role in T cell activation," Journal of Leukocyte Biology, vol. 84, no. 1, pp. 134-142, 2008.

[34] H. Haegel-Kronenberger, H. de la Salle, A. Bohbot, F. Oberling, J.-P. Cazenave, and D. Hanau, "Adhesive and/or signaling functions of CD44 isoforms in human dendritic cells," Journal of Immunology, vol. 161, no. 8, pp. 3902-3911, 1998.

[35] H. Guan, P. S. Nagarkatti, and M. Nagarkatti, "Role of CD44 in the differentiation of Th1 and Th2 cells: CD44-deficiency enhances the development of Th2 effectors in response to sheep RBC and chicken ovalbumin," Journal of Immunology, vol. 183, no. 1, pp. 172-180, 2009.

[36] S. Katoh, O. Kaminuma, T. Hiroi et al., "CD44 is critical for airway accumulation of antigen-specific Th2, but not Th1, cells induced by antigen challenge in mice," European Journal of Immunology, vol. 41, no. 11, pp. 3198-3207, 2011.

[37] E. R. Secor Jr., S. M. Szczepanek, A. Singh et al., "LC-MS/MS identification of a bromelain peptide biomarker from Ananas comosus Merr," Evidence-Based Complementary and Alternative Medicine, vol. 2012, Article ID 548486, 10 pages, 2012. 


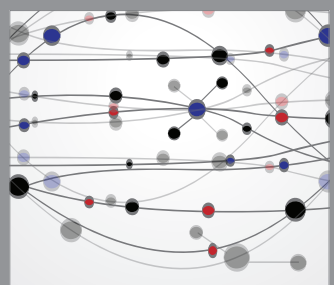

The Scientific World Journal
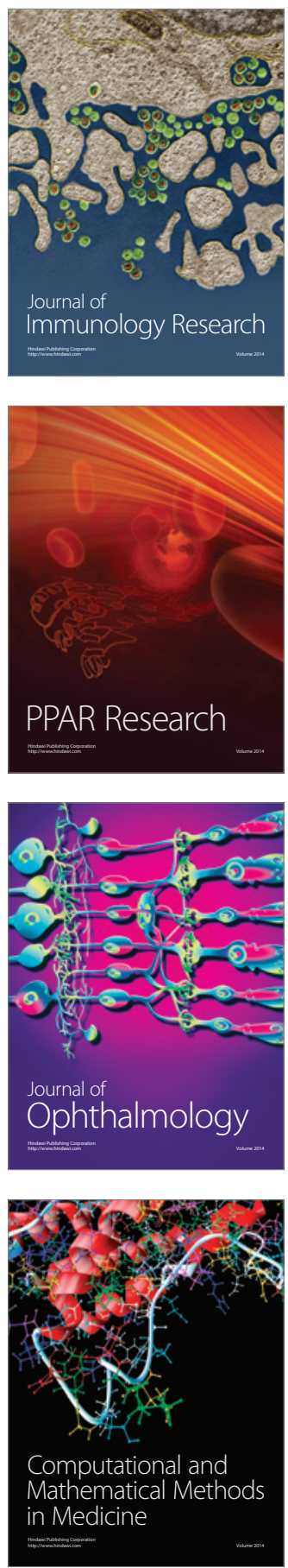

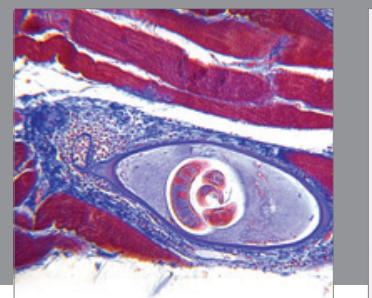

Gastroenterology

Research and Practice
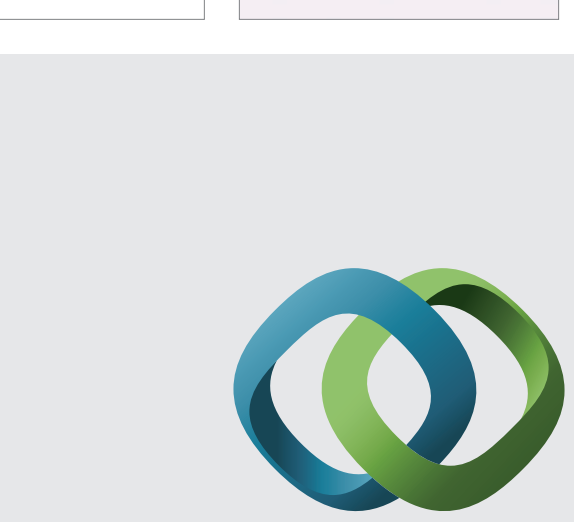

\section{Hindawi}

Submit your manuscripts at

http://www.hindawi.com
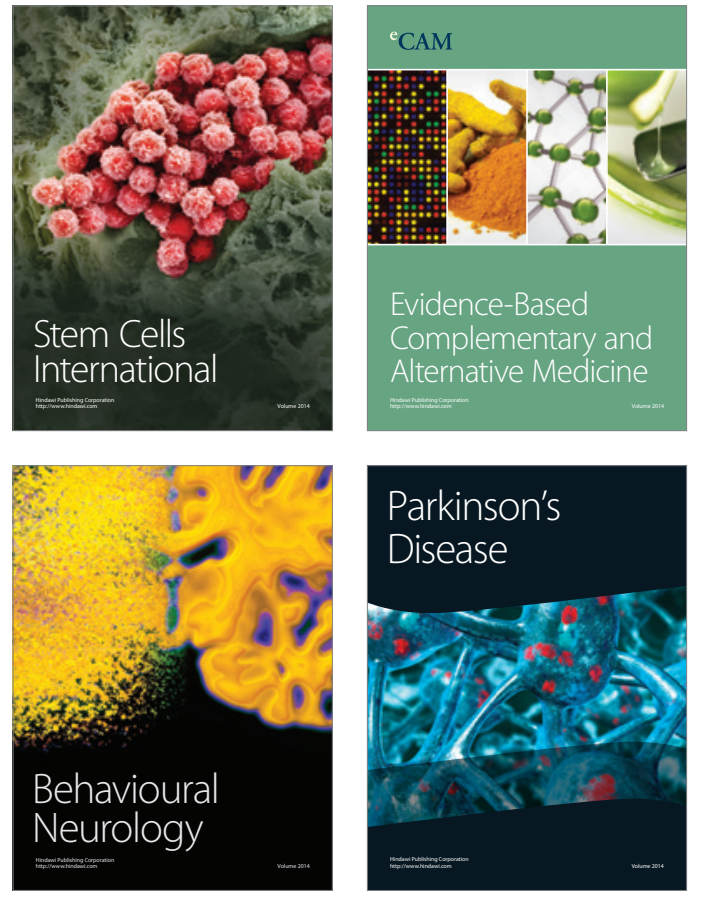
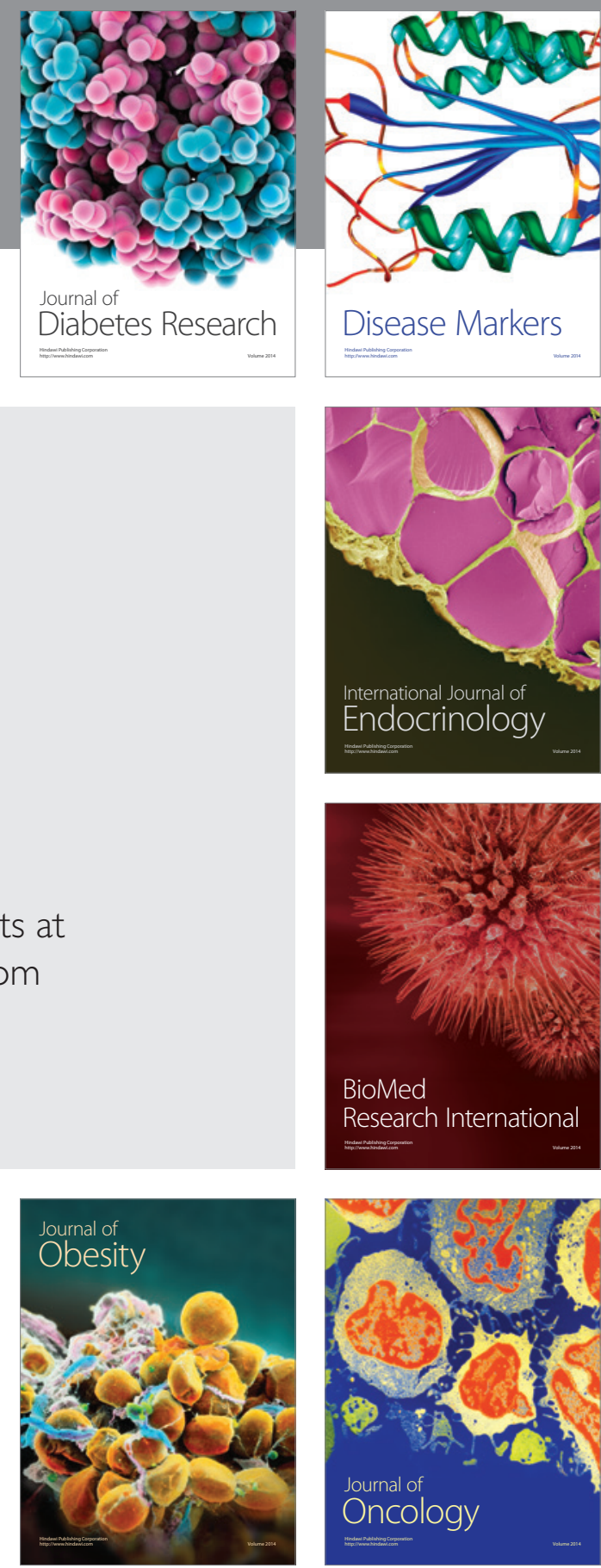

Disease Markers
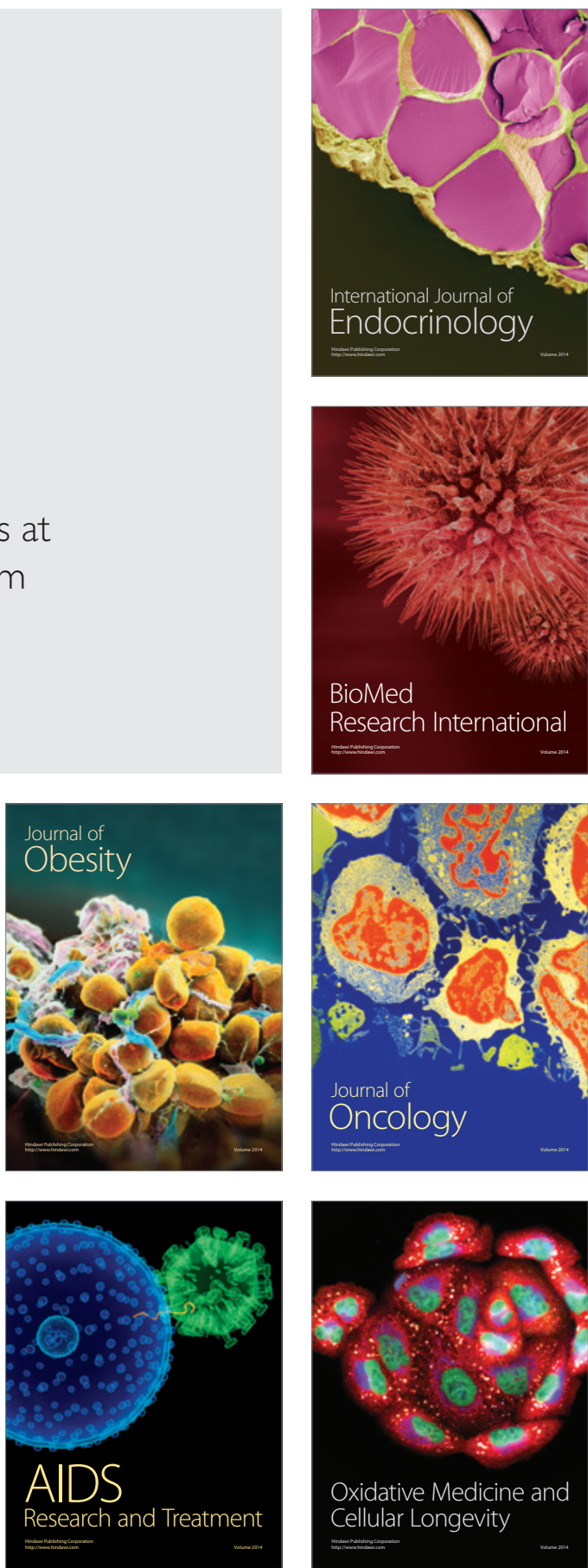